\title{
Correlation Between Pulpal and Carotid Arteries Blood Flow in Two Age Groups
}

\author{
Bojan Dželetović ${ }^{1}$, Nikola Aleksićㄹ, Djurica Grga ${ }^{1}$, Tatjana Savić-Stanković ${ }^{1}$, Ivana Milanović1, \\ Djordje Radak ${ }^{2}$ \\ 'University of Belgrade, Faculty of Dental Medicine, Department of Restorative Odontology and Endodontics, Belgrade, \\ Serbia; \\ ${ }^{2}$ Vascular Surgery Clinic, “Dedinje” Cardiovascular Institute, Belgrade, Serbia
}

\begin{abstract}
SUMMARY
Introduction Vascular network of dental pulp is supplied through common and external carotid artery and terminal dental branches that supply each pulp tissue. Age related changes of pulp tissue influence pulpal vascularization as well. The aim of this study was to compare and correlate pulpal and common and external carotid artery blood flow in young and middle age individuals of general population.

Material and Methods Two groups of 10 participants were included in the study, young (20-25 years) and middle age (50-55 years) group. Pulpal blood flow (PBF) measurements on intact right and left upper central incisors were performed using laser Doppler flowmetry (LDF) method. Carotid arteries blood flow was assessed using carotid ultrasonography.

Results PBF levels were significantly higher in young (3.11 \pm 0.67 and $3.46 \pm 1.11$, right and left upper central incisors, respectively) compared to middle age ( $1.93 \pm 0.47$ and $2.30 \pm 0.64$, right and left upper central incisors, respectively) participants (independent sample t test; $\mathrm{p}<0.05$ ). There was no correlation between common and external carotid artery blood flow and upper central incisors PBF in young as well as middle age participants, for right or left side.

Conclusion Absence of correlation between carotid arteries blood flow and PBF suggests that reduced PBF in middle age participants was probably not due to reduced blood supply from carotid arteries but it was result of age related changes at the level of pulpal blood vessels.
\end{abstract}

Keywords: dental pulp; blood flow; aging; carotid artery; laser Doppler flowmetry

\section{INTRODUCTION}

Dental pulp is well vascularized tissue with relatively high resting blood flow compared to other oral tissues [1]. Pulpal vasculature consists of arterial vessels that enter the pulp space through the apical foramina and additional blood vessels running into the pulp through lateral channels. From apical to coronal region of the pulp this network gives off numerous branches and terminates in a capillary plexus $[2,3]$. The pulp is enclosed within rigid walls of dentin and any change in blood vessels volume might result in disturbed tissue pressure, which in turn could affect capacity for regeneration turnover as well as the excitability of intradental nerves $[4,5]$. Such lowcompliance environment augments age-related changes that influence pulpal vascularization. As tooth gets older pulp space volume decrease [6] and consequently vascular, lymphatic and nerve supply is compromised $[7,8]$.

In common with all tissues, the ability of a tooth to survive is dependent of a viable blood supply. Vascular network of dental pulp is supplied through common carotid, external carotid and maxillary artery that gives terminal dental branches, which supply each individual pulp. Carotid arteries, as well as tissues they supply, are subjected to regressive structural and functional changes in the process of physiological aging $[9,10,11]$.

Up to date there are no data concerning relationship between PBF and carotid arteries blood flow in general population and the effect of aging on this relationship. Thus, the aim of this study was to compare and correlate pulpal and common and external carotid artery blood flow in young and middle age individuals of general population.

\section{MATERIAL AND METHODS}

\section{Participants}

Two groups of participants who were treated at the Department of restorative odontology and endodontics, School of Dentistry, University of Belgrade were enrolled in the study. The young group consisted of 5 male and 5 female healthy participants between 20 and 25 years of age. The middle age group consisted of 5 male and 5 female healthy participants between 50 and 55 years of 
age. Presence of any systemic disease or taking of any medication were general exclusion criteria, while caries, restorations, poor oral hygiene, gingivitis, periodontitis and tooth sensitivity of maxillary central incisors were local exclusion criteria. LDF recordings were performed at the Department of restorative odontology and endodontics, School of Dentistry, University of Belgrade while carotid ultrasonography recordings were performed at Vascular Surgery Clinic, "Dedinje" Cardiovascular Institute, Belgrade. The participants were informed about the procedures involved and informed consent was received. The protocol was approved by the Ethical Committee of School of Dentistry, University of Belgrade, and it was in accordance with the Helsinki Declaration of 1975.

\section{Laser Doppler flowmetry}

LDF recordings were done on healthy, intact upper central incisors. Tooth responsiveness to external stimuli was evaluated by conventional electrical and thermal tests. Radiographs were taken to determine normal periapical status of the tooth.

PBF measurements were performed with a laser Doppler flowmeter (PeriFlux PF 5001, Perimed, Jarfalla, Sweden). A 1-mW laser produced light of 623.8 $\mathrm{nm}$ wavelengths. A round probe (407-2, Perimed) with a cross-sectional diameter of $1 \mathrm{~mm}$ and 3 optical fibers with diameter of $125 \mu \mathrm{m}$ (fiber-to-fiber distance 250 $\mu \mathrm{m})$ were used. The active artifact filter and sampling frequency of $32 \mathrm{~Hz}$ were used. Before each data collection the flowmeter was calibrated to a specific value of 250 perfusion units (PU), with a colloidal suspension of latex micro particles (Perimed Motility Standard). The PBF was expressed in PU and monitored using data processing software (Perisoft Version 2.50; Perimed, Stockholm, Sweden). The mean PU values were determined using at least 3 minutes of recording.

For probe stabilization custom-made plastic splints (Bioplast, Schen-Dental, Iserlohn, Germany) were prepared providing appropriately placed holes with a diameter similar to that of the probe holder ( $\mathrm{pH}$ 07-6 Perimed, Sweden). Splint and the probe holder positioned the probe on the labial, cervical third of the tooth crown, perpendicular to the tooth surface. LDF measurements were performed with a rubber dam placed. After having participant rest in a supine position in dental chair for $10 \mathrm{~min}$, blood flow data were collected for at least $3 \mathrm{~min}$. The same dentist performed all measurements in an environment with constant temperature.

\section{Carotid ultrasonography}

Carotid arteries were examined bilaterally with a duplex ultrasound imaging (ALOKA, ALPHA 10) using a 4-7MHz linear array transducer. All recordings were performed with the participants in supine position, by the same trained sonographer. Scanning protocol of carotid arteries consisted of imaging in the longitudinal (antero-lateral, lateral, postero-lateral views) and transverse planes. The examination consisted of an initial exploratory scans of the carotid system, followed by measurement of blood volume flow (VF) rates. VF rates were measured using preset carotid ultrasound software (ALOKA, ALPHA 10) and a 4-7 MHz scan head, maintaining a $60^{\circ}$ angle of insonation. The sites of measurement were 1.0 to $1.5 \mathrm{~cm}$ below the carotid bifurcation for the common carotid artery (CCA) and 1.0 to $1.5 \mathrm{~cm}$ above the bifurcation for the external carotid artery (ECA). The carotid blood flow was expressed in $\mathrm{ml} / \mathrm{min}$.

\section{Statistical analysis}

Mean values of PBF, common carotid artery blood flow (ACC-VF) and external carotid artery blood flow (ACEVF) were obtained for the two participant groups and data were presented as mean \pm standard deviation (SD). Independent sample $t$ test was used to compare PBF, ACE-VF and ACC-VF between young and middle aged participants and Pearson's correlation to correlate PBF and ipsilateral ACC-VF as well as PBF and ipsilateral ACE-VF.

\section{RESULTS}

PBF, ACC-VF and ACE-VF for the two participant groups are shown in Table 1 and Table 2 for right and left side, respectively. $\mathrm{PBF}$ levels were significantly higher in young compared to middle age participants. ACC-VF and ACEVF were higher in middle age than young participants but there was no statistically significant difference between

Table 1. Pulpal blood flow (PBF) measured on the right upper central incisor, right common carotid artery blood flow (ACC-VF) and right external carotid artery blood flow (ACE-VF)

Tabela 1. Protok krvi kroz zubnu pulpu (PBF) meren na desnom gornjem centralnom sekutiću, kroz desnu zajedničku karotidnu arteriju (ACC-VF) i desnu spoljašnju karotidnu arteriju (ACE-VF)

\begin{tabular}{|l|c|c|c|}
\hline $\begin{array}{l}\text { Participants (years) } \\
\text { Ispitanici (godine) }\end{array}$ & PBF & ACC-VF & ACE-VF \\
\hline $\begin{array}{l}\text { Young (20-25) } \\
\text { Mladi (20-25) }\end{array}$ & $3.11 \pm 0.67$ & $533.20 \pm 105.39$ & $224.40 \pm 69.88$ \\
\hline $\begin{array}{l}\text { Middle-aged (50-55) } \\
\text { Srednje dobi (50-55) }\end{array}$ & $1.93 \pm 0.47^{*}$ & $562.90 \pm 62.25$ & $234.80 \pm 34.60$ \\
\hline
\end{tabular}

* independent sample t-test; $\mathrm{p}<0.05$

${ }^{*}$ t-test za nezavisne uzorke; $\mathrm{p}<0,05$

Table 2. Pulpal blood flow (PBF) measured on the left upper central incisor, left common carotid artery blood flow (ACC-VF) and left external carotid artery blood flow (ACE-VF)

Tabela 2. Protok krvi kroz zubnu pulpu (PBF) meren na levom gornjem centralnom sekutiću, kroz levu zajedničku karotidnu arteriju (ACC-VF) i levu spoljašnju karotidnu arteriju (ACE-VF)

\begin{tabular}{|l|c|c|c|}
\hline $\begin{array}{l}\text { Participants (years) } \\
\text { Ispitanici (godine) }\end{array}$ & PBF & ACC-VF & ACE-VF \\
\hline $\begin{array}{l}\text { Young (20-25) } \\
\text { Mladi (20-25) }\end{array}$ & $3.46 \pm 1.11$ & $537.60 \pm 128.86$ & $233.70 \pm 73.83$ \\
\hline $\begin{array}{l}\text { Middle-aged (50-55) } \\
\text { Srednje dobi (50-55) }\end{array}$ & $2.30 \pm 0.64^{*}$ & $606.70 \pm 70.00$ & $251.40 \pm 45.06$ \\
\hline
\end{tabular}

* independent sample $\mathrm{t}$-test; $\mathrm{p}<0.05$

* t-test za nezavisne uzorke; $\mathrm{p}<0,05$ 
Table 3. Correlations between upper central incisors pulpal blood flow (PBF) and ipsilateral common carotid artery blood flow (ACC$\mathrm{VF}$ ) and external carotid artery blood flow (ACE-VF), for the two groups of participants

Tabela 3. Korelacije između protoka krvi kroz zubnu pulpu gornjih centralnih sekutića i ipsilateralnog protoka krvi kroz zajedničku karotidnu arteriju (ACC-VF) i protoka krvi kroz spoljašnju karotidnu arteriju (ACE-VF) za dve grupe ispitanika

\begin{tabular}{|l|c|c|}
\hline $\mathbf{p}$ & ACC-VF & ACE-VF \\
\hline $\begin{array}{l}\text { Right incisor PBF Young (20-25) } \\
\text { PBF na desnom sekutiću mladih } \\
\text { ispitanika (20-25) }\end{array}$ & 0.311 & 0.869 \\
\hline $\begin{array}{l}\text { Left incisor PBF Young (20-25) } \\
\text { PBF na levom sekutiću mladih ispitanika } \\
\text { (20-25) }\end{array}$ & 0.774 & 0.913 \\
\hline $\begin{array}{l}\text { Right incisor PBF Middle-age (50-55) } \\
\text { PBF na desnom sekutiću ispitanika } \\
\text { srednje dobi (50-55) }\end{array}$ & 0.774 & 0.184 \\
\hline $\begin{array}{l}\text { Left incisor PBF Middle-age (50-55) } \\
\text { PBF na levom sekutiću ispitanika } \\
\text { srednje dobi (50-55) }\end{array}$ & 0.355 & 0.109 \\
\hline
\end{tabular}

the two groups. No significant correlation was found between ACC and ACE blood flow and upper central incisors $\mathrm{PBF}$ in young as well as middle age participants, for right or left side (Table 3 ).

\section{DISCUSSION}

The present study concerns the relationship between PBF and blood flow in common and external carotid artery in the two age groups, young and middle age, of general population. This objective was met by quantifying pulpal blood flow by LDF and blood flow in carotid arteries by high-resolution carotid ultrasonography. LDF method has been extensively used in dental traumatology, maxillofacial surgery and orthodontic force application, as a measure of pulp vitality and help in treatment decision [12, $13,14]$. This technique was considered to provide valid comparative data, although measurements are sensitive to physiological oscillations of blood pressure as well as movements during measurement [15]. High-resolution carotid ultrasonography is noninvasive, sensitive and reliable indicator of hemodynamic status of ipsilateral carotid, cerebral and maxillofacial circulation [16-19].

Many studies have reported association of oral diseases, such as periodontitis with coronary and carotid diseases [20-23]. Possible underlying mechanisms of such association include the presence of periodontal bacterial pathogens, antigens, bacterial toxins and the consequent inflammatory mediators production [24-27]. However, we sought to investigate the influence of carotid arteries hemodynamics, as feeding arteries, on the pulpal blood supply.

Our results showed that in the middle age participants, ACC and ACE blood flows were higher than in young participants, but the difference was not statistically significant. This could be attributed to the well functioning vascular network between carotid arteries and its terminal dental branches and anastomoses in this network. Our finding is in accordance with studies indicating that in healthy humans changes in ACC blood flow do not appear to be strongly correlated with age $[28,29,30]$.
On the other hand, the obtained results showed that upper central incisors PBF was significantly higher in younger than in older subjects, suggesting a clear age related decrease in PBF. Reduction of PBF levels with aging was also shown by Ikawa et al. [31], who suggested that observed PBF decrease was most probably underlined by age related changes in pulpal vascularity.

Major finding of our study is that there was no correlation between ACC and ACE blood flow and upper central incisors PBF in young as well as middle age participants. Concerning the fact that age related decrease in PBF existed, it could be proposed that reduced PBF in healthy, middle age participants was not due to reduced blood supply from ACC and ACE but it was result of age related changes at the level of pulpal blood vessels. Namely, early study of Bennett et al. [32] showed reduction in number of arteries supplying apical foramen in humans aged 1020 vs. $20-40$ vs. $40-70$ years, while thickening of arterial intimae and calcification of adventitia were observed from age $40[7,32]$. Also, histological studies have confirmed age related regressive changes in structure and number of pulpal blood vessels $[8,33]$. Measuring dentin deposition, Solheim found that coronal pulp cavity and pulp width strongly correlated with age [6]. Espina et al. showed that pulpal capillary endothelium experiences morphological changes during aging, such as increased transendothelial transport, cytoskeletal changes, hypertrophic Golgi complex and cytoplasmic deposits [34].

\section{CONCLUSION}

Since there is no age related reduction in ACC and ACE blood flow, observed reduction in upper central incisors $\mathrm{PBF}$, in middle age (50-55) general population, is the most likely the consequence of age related changes in dental pulp microcirculation.

\section{REFERENCES}

1. Tonder KJ. Blood flow and vascular pressure in the dental pulp. Summary. Acta Odontol Scand. 1980; 38:135-44. [DOI: 10.3109/00016358009004712] [PMID: 6998253]

2. Corpron RE, Avery JK, Lee SD. Ultrastructure of capillaries in the odontoblastic layer. J Dent Res. 1973; 52:393. [PMID: 8769670]

3. Yoshida S, Ohshima H. Distribution and organization of peripheral capillaries in dental pulp and their relationship to odontoblasts. Anat Rec. 1996; 245:313-26.

[DOI: 10.1002/(SICI)1097-0185(199606)245:2<313.:AIDAR14>3.0.CO;2-S] [PMID: 8769670]

4. Olgart L. Neural control of pulpal blood flow. Crit Rev Oral Biol Med. 1996; 7:159-71. [PMID: 8875030]

5. Ahlquist M, Franzen O. Pulpal ischemia in man: effects on detection threshold, A-delta neural response and sharp dental pain. Endod Dent Traumatol. 1999; 15:6-16. [PMID: 10219148]

6. Solheim T. Amount of secondary dentin as an indicator of age. Scand J Dent Res. 1992; 100:193-9. [PMID: 1439521]

7. Ketterl W. Age-induced changes in the teeth and their attachment apparatus. Int Dent J. 1983; 33:262-71. [PMID: 6579031]

8. Saad AY. Regressive changes of the dental pulp complex in retained primary molars with congenitally missing successor teeth. J Clin Pediatr Dent. 1997; 22:63-7. [PMID: 9643208] 
9. Taddei S, Virdis A, Ghiadoni L, Versari D, Salvetti A. Endothelium, aging, and hypertension. Curr Hypertens Rep. 2006; 8:84-9. [PMID: 16600164]

10. Greenwald SE. Ageing of the conduit arteries. J Pathol. 2007; 211:157-72. [DOI: 10.1002/path.2101] [PMID: 17200940]

11. O'Rourke MF. Arterial aging: pathophysiological principles. Vasc Med. 2007; 12:329-41. [DOI: 10.1177/1358863X07083392] [PMID: 18048471]

12. Sano Y, Ikawa M, Sugawara J, Horiuchi H, Mitani $H$. The effect of continuous intrusive force on human pulpal blood flow. Eur J Orthod. 2002; 24:159-66. [DOl: 10.1093/ejo/24.2.159] [PMID: 12001552]

13. Harada K, Sato M, Omura K. Blood-flow and neurosensory changes in the maxillary dental pulp after differing Le Fort I osteotomies. Oral Surg Oral Med Oral Pathol Oral Radiol Endod. 2004; 97:12-7. [DOl: 10.1016/j.tripleo.2003.08.028] [PMID: 14716251]

14. Emshoff R, Moschen I, Strobl H. Treatment outcomes of dental injury diagnoses as related to blood flow measurements from teeth. J Oral Rehabil. 2008; 35:209-17.

[DOI: 10.1111/j.1365-2842.2007.01757.x] [PMID: 18254799]

15. Emshoff R, Emshoff I, Moschen I, Strobl H. Diagnostic characteristics of pulpal blood flow levels associated with adverse outcomes of luxated permanent maxillary incisors. Dent Traumatol. 2004; 20:270-5. [DOI: 10.1111/j.1600-9657.2004.00281.x] [PMID: 15355386]

16. Howard G, Sharrett AR, Heiss G, Evans GW, Chambless LE, Riley WA, et al. Carotid artery intimal-medial thickness distribution in general populations as evaluated by B-mode ultrasound. ARIC Investigators. Stroke. 1993; 24:1297-304. [PMID: 8362421]

17. Chu BC, Narita A, Aoki K, Yoshida T, Warabi T, Miyasaka K. Flow volume in the common carotid artery detected by color duplex sonography: an approach to the normal value and predictability of cerebral blood flow. Radiat Med. 2000; 18:239-44. [PMID: 11246999]

18. Soder PO, Soder B, Nowak J, Jogestrand T. Early carotid atherosclerosis in subjects with periodontal diseases. Stroke. 2005; 36:1195-200. [DOI: 10.1161/01.STR.0000165916.90593.cb] [PMID: 15879347]

19. Eigenbrodt ML, Bursac Z, Tracy RE, Mehta JL, Rose KM, Couper DJ. B-mode ultrasound common carotid artery intima-media thickness and external diameter: cross-sectional and longitudinal associations with carotid atherosclerosis in a large population sample. Cardiovasc Ultrasound. 2008; 6:10. [DOl: 10.1186/1476-7120-6-10] [PMID: 18321381]

20. Mattila KJ, Valtonen VV, Nieminen M, Huttunen JK. Dental infection and the risk of new coronary events: prospective study of patients with documented coronary artery disease. Clin Infect Dis. 1995; 20:588-92. [PMID: 7756480]

21. Joshipura KJ, Rimm EB, Douglass CW, Trichopoulos D, Ascherio A, Willett WC. Poor oral health and coronary heart disease. J Dent Res. 1996; 75:1631-6. [PMID: 8952614]
22. Loesche WJ, Schork A, Terpenning MS, Chen YM, Kerr C, Dominguez $\mathrm{BL}$. The relationship between dental disease and cerebral vascular accident in elderly United States veterans. Ann Periodontol. 1998; 3:161-74. [PMID: 9722700]

23. Morrison HI, Ellison LF, Taylor GW. Periodontal disease and risk of fatal coronary heart and cerebrovascular diseases. J Cardiovasc Risk. 1999; 6:7-11. [PMID: 10197286]

24. Chiu B. Multiple infections in carotid atherosclerotic plaques. Am Heart J. 1999; 138:S534-6. [PMID: 10539867]

25. Offenbacher S, Madianos PN, Champagne CM, Southerland JH, Paquette DW, Williams RC, et al. Periodontitis-atherosclerosis syndrome: an expanded model of pathogenesis. J Periodontal Res. 1999; 34:346-52. [PMID: 10685359]

26. Haraszthy VI, Zambon J), Trevisan M, Zeid M, Genco RJ. Identification of periodontal pathogens in atheromatous plaques. J Periodontol. 2000; 71:1554-60. [PMID: 11063387]

27. Cairo F, Gaeta C, Dorigo W, Oggioni MR, Pratesi C, Pini Prato GP, et al. Periodontal pathogens in atheromatous plaques. A controlled clinical and laboratory trial. J Periodontal Res. 2004; 39:442-6. [DOI: 10.1111/j.1600-0765.2004.00761.x] [PMID: 15491349]

28. Schoning $M$, Walter J, Scheel P. Estimation of cerebral blood flow through color duplex sonography of the carotid and vertebral arteries in healthy adults. Stroke. 1994; 25:17-22. [PMID: 8266366]

29. Schoning M, Hartig B. Age dependence of total cerebral blood flow volume from childhood to adulthood. J Cereb Blood Flow Metab. 1996; 16:827-33. [PMID: 8784227]

30. Schoning $M$, Hartig B. The development of hemodynamics in the extracranial carotid and vertebral arteries. Ultrasound Med Biol. 1998; 24:655-62.

[DOI: 10.1016/S0301-5629(98)00029-5] [PMID: 9695268]

31. Ikawa M, Komatsu H, Ikawa K, Mayanagi H, Shimauchi H. Age-related changes in the human pulpal blood flow measured by laser Doppler flowmetry. Dent Traumatol. 2003; 19:36-40.

[DOI: 10.1034/j.1600-9657.2003.00120.x] [PMID: 12656853]

32. Bennett CG, Kelln EE, Biddington WR. Age changes of the vascular pattern of the human dental pulp. Arch Oral Biol. 1965; 10:995-8. [DOI: 10.1016/0003-9969(65)90093-2] [PMID: 5227002]

33. Bernick S. Age changes in the blood supply to human teeth. J Dent Res. 1967; 46:544-50. [DOl: 10.1177/00220345670460031501] [PMID: 5338250]

34. Espina Al, Castellanos AV, Fereira JL. Age-related changes in blood capillary endothelium of human dental pulp: an ultrastructural study. Int Endod J. 2003; 36:395-403. [DOI: 10.1046/j.1365-2591.2003.00659.x] [PMID: 12801286]

Received: 24/06/2015 • Accepted: 07/09/2015 


\title{
Nivo protoka krvi kroz zubnu pulpu i njegova korelacija s protokom krvi kroz karotidne arterije kod dve starosne grupe opšte populacije
}

\author{
Bojan Dželetović', Nikola Aleksić2 , Đurica Grga', Tatjana Savić-Stanković1, Ivana Milanović1, \\ Đorđe Radak ${ }^{2}$ \\ 'Univerzitet u Beogradu, Stomatološki fakultet, Klinika za bolesti zuba i endodonciju, Beograd, Srbija; \\ ${ }^{2}$ Klinika za vaskularnu hirurgiju, Institut za kardiovaskularne bolesti „Dedinje“, Beograd, Srbija
}

\begin{abstract}
KRATAK SADRŽAJ
Uvod Vaskularna mreža zubne pulpe dobija dotok krvi preko zajedničke i spoljašnje karotidne arterije i završnih zubnih grana koje snabdevaju svaku pojedinačnu pulpu. Mala fleksibilnost okruženja zubne pulpe pojačava promene vezane za starenje koje utiču na vaskularizaciju pulpe. Cilj ovog rada je bio da se uporedi i utvrdi međusobna povezanost pulpnog i protoka krvi u zajedničkoj i spoljašnjoj karotidnoj arteriji kod mladih i osoba srednje životne dobi opšte populacije.

Materijal i metode rada Dve grupe od po 10 ispitanika su učestvovale u studiji: mladi (20-25 godina) i ispitanici srednje životne dobi (50-55 godina). Merenja protoka krvi kroz zubnu pulpu (PBF) na intaktnim desnim i levim gornjim centralnim sekutićima izvedena su metodom laser Dopler floumetrije (LDF). Protok krvi kroz karotidne arterije je procenjivan ultrazvučnim pregledom. Rezultati Nivoi PBF bili su značajno viši kod mladih ispitanika (desni gornji centralni sekutići: 3,11 $\pm 0,67$; levi gornji centralni sekutići:

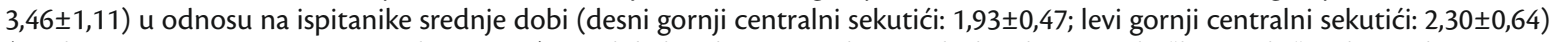
(Studentov $t$-test za nezavisne uzorke, $p<0,05$ ). Nije bilo korelacije između protoka krvi kroz zajedničke i spoljašnje karotidne arterije i PBF gornjih sekutića kod mladih, niti kod ispitanika srednje dobi, za desnu i levu stranu.

Zaključak Nepostojanje veze između protoka krvi kroz karotidne arterije i PBF ukazuje na to da smanjenje PBF kod ispitanika srednje životne dobi verovatno nije posledica smanjenog dotoka krvi iz karotidnih arterija, već rezultat promena u vezi sa starenjem na nivou pulpnih krvnih sudova.
\end{abstract}

Ključne reči: zubna pulpa; protok krvi; starenje; karotidna arterija; laser Dopler floumetrija

\section{UVOD}

Zubna pulpa je dobro vaskularizovano tkivo s relativno visokim osnovnim protokom krvi u poređenju sa drugim oralnim tkivima [1]. Pulpna vaskularna mreža se sastoji od arterija koje ulaze u prostor komore pulpe kroz apikalne otvore i dodatnih krvnih sudova koji ulaze u pulpu kroz bočne kanale. Od apikalne do koronarne regije pulpe ova mreža daje brojne grane i završava se kapilarnim pleksusom [2,3]. Pulpa je zatvorena unutar čvrstih dentinskih zidova i bilo kakve promene u volumenu krvnih sudova mogu dovesti do poremećaja u tkivnom pritisku, što zauzvrat može uticati na regenerativne sposobnosti i nadražljivost intradentalnih nerava [4,5]. Takvo slabo fleksibilno okruženje dodatno naglašava promene vezane za starenje koje utiču na vaskularizaciju pulpe. Starenjem zuba pulpna komora se smanjuje [6], a posledično je ugrožena i vaskularna, limfna i nervna mreža pulpe $[7,8]$.

Kao i kod svih tkiva, sposobnost zuba da opstane zavisi od održivog dotoka krvi. Vaskularna mreža zubne pulpe se ishranjuje preko zajedničke i spoljašnje karotidne arterije i maksilarne arterije, koja daje završne zubne grane koje snabdevaju svaku pojedinačnu pulpu. Karotidne arterije, kao i tkiva koja ishranjuju, podležu regresivnim strukturnim i funkcionalnim promenama u procesu fiziološkog starenja $[9,10,11]$.

Do danas ne postoje podaci o odnosu između protoka krvi kroz zubnu pulpu (PBF) i protoka krvi kroz karotidne arterije u opštoj populaciji, kao ni o efektu starenja na taj odnos. Stoga je cilj ovog istraživanja bio da se uporedi i utvrdi međusobna povezanost pulpnog i protoka krvi u zajedničkoj i spoljašnjoj karotidnoj arteriji kod mladih i pojedinaca srednje životne dobi opšte populacije.

\section{MATERIJAL I METODE RADA}

\section{Ispitanici}

Dve grupe ispitanika koji su bili lečeni na Klinici za bolesti zuba Stomatološkog fakulteta Univerziteta u Beogradu učestvovale su u studiji. Grupa mladih zdravih ispitanika sastojala se od pet muškaraca i pet žena starosti između 20 i 25 godina. Grupa zdravih ispitanika srednje životne dobi sastojala se od pet muškaraca i pet žena starosti između 50 i 55 godina. Postojanje bilo koje sistemske bolesti ili korišćenje bilo kakvih lekova bili su opšti kriterijumi za isključenje iz studije, dok su karijes, restauracije, loša oralna higijena, gingivitis, parodontitis i osetljivost gornjih centralnih sekutića bili lokalni kriterijumi za isključenje. Snimanja laser Dopler floumetrijom (LDF) su urađena na Klinici za bolesti zuba i endodonciju Stomatološkog fakulteta Univerziteta u Beogradu, dok su ultrazvučni pregledi karotidnih arterija urađeni na Klinici za vaskularnu hirurgiju Instituta za kardiovaskularne bolesti „Dedinje“ u Beogradu. Ispitanici su bili upoznati s protokolom istraživanja i dali su svoj pisani pristanak za učestvovanje u studiji. Protokol je odobrio Etički odbor Stomatološkog fakulteta Univerziteta u Beogradu, i on je bio u skladu s Helsinškom deklaracijom iz 1975. godine.

\section{Laser Dopler floumetrija}

LDF snimanja su rađena na zdravim, intaktnim gornjim centralnim sekutićima. Reakcija zuba na nadražaje procenjena je konvencionalnim elektro i termo testovima. Radiogramima je potvrđeno normalno stanje periapeksa zuba. 
Merenja PBF izvedena su laser Dopler meračem protoka ( $P e$ riFlux PF 5001, Perimed, Jarfala, Švedska). Svetlo talasne dužine od $623.8 \mathrm{~nm}$ proizvodio je 1-mW laser. Korišćena je okrugla sonda (407-2, Perimed) s poprečnim presekom od $1 \mathrm{~mm}$ i tri optička vlakna promera $125 \mu \mathrm{m}$ (udaljenost vlakna od vlakna bila je $250 \mu \mathrm{m}$ ). Artefakt filter je bio aktiviran, a učestalost merenja je bila $32 \mathrm{~Hz}$. Pre svakog prikupljanja podataka merač protoka je kalibrisan na određenu vrednost od 250 perfuzionih jedinica (PU), s koloidnom suspenzijom lateks mikročestica (Perimed Motility Standard). PBF je izražavan u PU i praćen pomoću softvera za obradu podataka (Perisoft verzija 2,50, Perimed, Stokholm, Švedska). Prosečne vrednosti protoka određivane su korišćenjem najmanje tri minuta snimljenog zapisa.

Za stabilizaciju sonde izrađivan je individualni splint od tvrde plastike (Bioplast, Schen-Dental, Izerlon, Nemačka) sa odgovarajuće postavljenim rupama promera sličnog promeru držača sonde ( $\mathrm{pH}$ 6/7, Perimed, Švedska). Splint i držač sonde pozicionirali su sondu na labijalnoj, vratnoj trećini krunice, upravno na površinu zuba. LDF merenja su izvedena uz korišćenje koferdama. Nakon odmora ispitanika od 10 minuta u ležećem položaju, u stomatološkoj stolici, protok krvi je meren tokom najmanje tri minuta. Sva merenja izvedena su pri konstantnoj ambijentalnoj temperaturi od strane istog stomatologa.

\section{Ultrazvučni pregled karotidnih arterija}

Karotidne arterije su ispitivane bilateralno ultrazvučnim aparatom (ALOKA, ALPHA 10) pomoću linearne sonde od 4-7 MHz. Sva snimanja su izvedena na ispitanicima u ležećem položaju od strane istog iskusnog lekara. Protokol se sastojao od snimanja karotidnih arterija u uzdužnoj (anterolateralnom, bočnom, posterolateralnom pogledu) i poprečnoj ravni. Ispitivanje se sastojalo od inicijalnog snimanja karotidnog sistema, nakon čega je sledilo merenje protoka krvi (VF). Protok krvi je meren pomoću softvera (ALOKA, ALPHA 10) i sonde od $4-7 \mathrm{MHz}$, održavajući ugao insonacije od $60^{\circ}$. Mesta merenja su bila od 1,0 do $1,5 \mathrm{~cm}$ ispod karotidne bifurkacije za zajedničku karotidnu arteriju (CCA) i od 1,0 do 1,5 cm iznad bifurkacije za spoljašnju karotidnu arteriju (ECA). Protok krvi kroz karotidne arterije je izražavan $\mathrm{u} \mathrm{ml} / \mathrm{min}$.

\section{Statistička analiza}

Računate su srednje vrednosti PBF, protoka krvi kroz zajedničku karotidnu arteriju (ACC-VF) i protoka krvi kroz spoljašnju karotidnu arteriju (ACE-VF) za dve grupe ispitanika, a podaci su prikazani kao srednja vrednost \pm standardna devijacija (SD). Studentov t-test za nezavisne uzorke korišćen je za poređenje PBF, ACC-VF i ACE-VF između mladih i ispitanika srednje životne dobi, a Pirsonov (Pearson) test za korelaciju PBF i ipsilateralnog ACC-VF, kao i PBF i ipsilateralnog ACE-VF.

\section{REZULTATI}

Rezultati PBF, ACC-VF i ACE-VF kod dve grupe ispitanika prikazani su u tabelama 1 i 2 za desnu i levu stranu. Nivoi PBF bili su značajno viši kod mladih ispitanika u odnosu na ispitanike srednje dobi. ACC-VF i ACE-VF su bili veći kod ispitanika srednje dobi nego kod mladih, ali nije bilo statistički značajne razlike između grupa. Nije utvrđena značajna korelacija između ACC i ACE protoka krvi i PBF gornjih centralnih sekutića ni kod mladih, ni kod ispitanika srednje dobi, kako za desnu, tako i za levu stranu (Tabela 3).

\section{DISKUSIJA}

Cilj ove studije je bio da istraži odnos između PBF i protoka krvi u zajedničkoj i spoljašnjoj karotidnoj arteriji u dve starosne grupe - kod mladih i ispitanika srednje dobi u opštoj populaciji. Ovaj cilj je ispunjen određivanjem protoka krvi kroz zubnu pulpu pomoću LDF metode i protoka krvi kroz karotidne arterije pomoću ultrazvučnog pregleda. LDF metoda je opsežno korišćena u dentalnoj traumatologiji, maksilofacijalnoj hirurgiji i ortodonciji kao merilo vitaliteta pulpe i pomoć u terapiji $[12,13$, 14]. Smatra se da ova tehnika daje valjane, uporedive podatke, iako su merenja osetljiva na fiziološke oscilacije krvnog pritiska, kao i na pokretanje ispitanika tokom merenja [15]. Ultrazvučni pregled karotidnih arterija je neinvazivan, vrlo osetljiv i pouzdan pokazatelj hemodinamskog statusa ipsilateralne karotidne, moždane i cirkulacije u maksilofacijalnoj regiji [16-19].

Mnoge studije su proučavale povezanost oralnih bolesti, kao što je parodontitis, s koronarnom i karotidnom bolešću [20-23]. Mogući mehanizmi takve povezanosti su parodontalni bakterijski patogeni, antigeni, bakterijski toksini i posledična proizvodnja medijatora zapaljenja [24-27]. Međutim, u ovom radu namera je bila da se ispita uticaj hemodinamike karotida, kao dovodnih arterija, na dotok krvi u zubnu pulpu.

Rezultati su pokazali da je kod ispitanika srednje životne dobi protok krvi kroz ACC i ACE bio veći nego kod mladih ispitanika, ali razlika nije bila statistički značajna. To se može pripisati dobroj funkcionalnosti vaskularne mreže između karotidnih arterija i njihovih terminalnih zubnih grana i anastomozama ove mreže. Ovaj nalaz je u skladu s istraživanjima koja su pokazala da kod zdravih ljudi promene protoka krvi kroz ACC nisu značajno povezane sa starosnom dobi [28, 29, 30].

S druge strane, dobijeni rezultati su pokazali da je PBF centralnih gornjih sekutića bio značajno veći kod mladih nego kod starijih ispitanika, što jasno ukazuje na smanjenje PBF uslovljeno starenjem. Smanjenje nivoa PBF sa starenjem takođe su pokazali Ikava (Ikawa) i saradnici [31] tumačeći uočeno smanjenje PBF kao verovatno uslovljeno promenama u vaskularizaciji pulpe usled starenja.

Glavni nalaz ove studije je da ne postoji korelacija između protoka krvi u ACC i ACE i PBF gornjih sekutića kod mladih, kao ni kod ispitanika srednje dobi. Imajući u vidu postojanje smanjenja PBF usled starenja, moglo bi se pretpostaviti da kod zdravih ispitanika srednje dobi ono nije uzrokovano smanjenim dotokom krvi iz ACC i ACE, već je rezultat promena na nivou pulpnih krvnih sudova uzrokovanih starenjem. Naime, rana studija Beneta (Bennett) i saradnika [32] pokazala je smanjenje broja arterija koje ulaze u pulpu kroz apikalni otvor kod ljudi uzrasta 10-20 godina u odnosu na ispitanike starosti 20-40 i 40-70 godina, dok su zadebljanje intime arterija i kalcifikacije adventicije uočeni kod starijih od 40 godina [7]. Autori su 
takođe u histološkim studijama pokazali regresivne promene vezane za starenje u strukturi i broju krvnih sudova pulpe [8, 33]. Merenjem depozicije dentina, Zolhajm (Solheim) [6] je pronašao korelaciju širine pulpne komore i starosti. Espina (Espina) i saradnici [34] su otkrili da sa starenjem kapilarni endotel pulpe doživljava morfološke promene, kao što su povećan transendotelni transport, promene citoskeleta, hipertrofija Goldžijevog kompleksa i citoplazmatskih depozita.

\section{ZAKLJUČAK}

Budući da nije bilo smanjenja protoka krvi u ACC i ACE vezanog za starenje, uočeno smanjenje PBF gornjih centralnih sekutića kod ispitanika srednje životne dobi (50-55) opšte populacije verovatno je posledica promena vezanih za starenje $\mathrm{u}$ mikrocirkulaciji zubne pulpe. 